\title{
Epistemic Emotions: The Case of Wonder
}

\author{
Emoções Epistêmicas: O caso da Maravilha
}

\author{
LAURA CANDIOTTO ${ }^{a}$
}

\begin{abstract}
In this paper I discuss the reasons for which we may consider wonder an epistemic emotion. I defend the thesis for which a specific type of wonder is aporia-based and that since it is aporia-based, this wonder is epistemic. The epistemic wonder is thus an interrogating wonder which plays the epistemic function of motivation to questioning in processes of inquiry. I first introduce the contemporary debate on epistemic emotions, and then I analyze the characteristics that make of wonder an epistemic emotion, from a data-based, phenomenological, and conceptual perspective.
\end{abstract}

Keywords: Wonder. Epistemic emotion. Aporia. Inquiry. Suffering.

\section{Resumo}

Neste artigo, discuto as razões pelas quais podemos considerar a maravilha uma emoção epistêmica. Defendo a tese pela qual um tipo específico de maravilha é baseado numa aporia e que, como é baseado em aporia, essa maravilha é epistêmica. A maravilha epistêmica é, portanto, uma maravilha interrogativa que desempenha a função epistêmica da motivação para questionar nos processos de investigação. Introduzo primeiro o debate contemporâneo sobre emoções epistêmicas e, em seguida, analiso as características que fazem da maravilha uma emoção epistêmica de uma perspectiva baseada em dados fenomenológico e conceitual.

Palavras-chave: Maravilha. Emoção epistêmica. Aporia. Inquérito. Sofrimento.

\footnotetext{
a Free University of Berlin, Berlin, Germany. PhD in Philosophy, e-mail: laura.candiotto@fuberlin.de
} 


\section{Introduction}

A few months ago, I was walking through the Gärten der Welt in Berlin and, arrived at the Chinese Garden's little shop, I was struck by a postcard, a picture of T a few autumns leaves with the following maxim: "Everything is full of wonder." Looking at this postcard, I had a feeling of why everything can be full of wonder, but as a philosopher, I wanted to know more about it. So, I started to wonder how can a small thing as a leaf trigger wonder and, also, how can a dead leaf do so.

This experience is not extrinsic to this paper's topic. In this paper, I am going to argue that a specific type of wonder is aporia-based and that since it is aporiabased, this wonder is epistemic. Let me come back once again to my experience. The postcard has caught my attention, maybe because the meaning of the phrase was significant to me at that moment, or maybe because the colors of the image were warm and welcoming. It is not essential to establish it now. What is meaningful is that something unclear, strange, and new activated my thinking, and I started to ask myself questions - I started to wonder about wonder.

From Plato to Aristotle, and then throughout the history of philosophy, wonder has been identified as the beginning of philosophy since it triggers the process of inquiry (Candiotto \& Politis, forthcoming). In this paper, I do not analyze this important philosophical heritage on wonder, but I discuss the reasons for which we may be allowed to think that this wonder is epistemic. In doing so, I will first briefly introduce the contemporary debate on epistemic emotions, and then I will analyze the characteristics that seem to make of wonder an epistemic emotion, also considering some objections.

\section{Epistemic emotions}

Let us start with some definitions. If an emotion is labeled as epistemic, this means that the emotion plays an epistemic function. It does not mean that the emotion accidentally occurs in epistemic contexts, but most fundamentally, that the epistemic function defines what the emotion is. Not all the emotions are epistemic: some emotions play epistemic functions, certain most intrinsically, like curiosity, 
other in specific situations, that is when they play a decisive role in our epistemic activities, like shame in critical dialogue for example. ${ }^{1}$ This means that the boundaries of the category of epistemic emotions allow a stronger and a weaker definition of epistemic emotions. For discriminating between these two definitions, it is crucial to recognize the epistemic function supposedly enacted by the emotion.

For Morton (2010), epistemic emotions are a source of salience and interest in a topic. The epistemic function played by epistemic emotions is thus the one of motivation to knowing, and their intentionality is defined by having the truth as their formal object (Candiotto 2019a) ${ }^{2}$. This is the strong definition of epistemic emotions, and it highlights that it can be ascribed to epistemic emotions a causal role in knowledge acquisition. This role is clear if we think of epistemic emotions as what motivate the epistemic practices. Consequently, epistemic emotions are motivations for finding the correct answer to our curiosity/interest/concern or developing the best argument in favor of a thesis, for example. Also other roles can be ascribed to epistemic emotions, as a justificatory role, that means that epistemic emotions can justify our judgments about what is certain or doubtful, for example. ${ }^{3}$ Regarding this point, the feeling of familiarity, the feeling of knowing, and the joy of verification can be good examples.

Although I think that conceptualizing epistemic emotions as those emotions which are directed at knowing is convincing (see Candiotto 2017a), I am aware it is quite demanding. In fact, it strictly relates the emotions to the final object of knowledge. We can thus look at the emotion's epistemic function from a different

\footnotetext{
${ }^{1}$ It may be objected that curiosity is not an emotion, but a metacognitive feeling, for example. I cannot discuss the wide debate on what is emotion here, neither the one on curiosity, but I rely on Morton (2010) who first defined what is an epistemic emotion and brought curiosity as example. Regarding the epistemic function of shame in critical dialogue, see Candiotto 2019c. For a variety of perspectives on the claim that emotions play a positive role in the epistemic activities, see the edited collections by Brun et al. 2008 and Candiotto 2019b.

2 The notion of "epistemic emotions" has been introduced in the contemporary debate by Morton (2010). We can find in the literature a debate on them before Morton as "intellectual emotions" (Stocker 2004), or "cognitive emotions" (Scheffler 1991). Others have preferred to understand them as epistemic feelings (de Sousa 2008) or metacognitive feelings, and the debate regarding the taxonomy of these states is still ongoing. Also, they have been studied in conjunction with other general topics in epistemology (see for example Hookway 2003).

3 The perceptual model is the usual way of defending a justificatory role of emotions. See on this Tappolet (2000), Johnston (2001), Deonna (2006), and Döring (2007). This view has been widely criticized, and the debate between the opponents and the defendants is still ongoing. For the reconstruction of the debate, see Mitchell 2017.
} 
and more pluralist perspective, the one which looks at the many epistemic functions that can be ascribed to emotions in the epistemic practices, like evaluation, deliberation, and beliefs' revision (Hookway 2008; Livet 2016), and not just at their final epistemic object. In this way we will find many emotions which play epistemic functions, as when we judge a situation as dangerous if we feel fear, we chose to make a present to our partner because we are happy, or when we change our mind about something when we feel dissatisfied with our epistemic standing. In these cases, emotions which are not immediately related to knowledge achievement, as fear and happiness, can nevertheless be recognized as epistemic. The feeling of doubt which is presumably felt in the beliefs' revision is certainly closest to epistemic goals than fear and happiness, but it should not be taken for granted that it is directed to the truth.

This definition of epistemic emotion is weaker than the previous one but has the benefit of highlighting the epistemicity of many emotions and thus contrasting the traditional view about the detrimental role of emotions in knowledge. The picture is, therefore, the one which looks at the integration of emotions in the epistemic processes, whatever kind of emotions they are. Although I do think that the stronger definition of epistemic emotions is more precise and that the weaker is too broad, in this paper I am not going to argue for the validity of the one instead of the other, but I will show why a specific kind of wonder can legitimately be an instantiation of the stronger definition.

A last point should be mentioned before moving to this central thesis. Emotions do not need to do all the job for being identified as epistemic. For example, Brady (2009, 2013, 2018a) has argued that emotions can facilitate evaluative understanding since they help the epistemic agent to focus on a topic and struggle for grasping it. If emotions are "helpers", then other skills are required for successfully know-why, like critical thinking, assessment of arguments, and understanding of the chains of cause and effect, for example. However, this does not deny that emotions play an important epistemic function in the process. What is a matter of debate, instead, is the determination of this function. My position is that we need to study specific emotions in well-defined epistemic practices and contexts. 
I think that we can provide a general answer about the function of emotions in knowledge and opting for the stronger or the weaker definition of epistemic emotions. But I also think that this is not enough and that we need to study specific cases for fine graining our analysis. The study of the role of wonder in inquiry I am pursuing in this paper goes precisely in this direction.

\section{Wonder as an epistemic emotion}

As I have already highlighted, both Plato and Aristotle have thought of wonder as the beginning of philosophy. The epistemic function ascribed to wonder is thus the one to initiate the process of inquiry. But is it really the case? Is wonder the beginning and the cause of this fundamental epistemic practice which is inquiry?

My answer says that this is not the case for whatever kind of wonder, but that it is true iff wonder is in conjunction with an aporetic state or with a problem to solve. For "aporetic state", I mean a disruptive mental state wherein one faces some contradiction that one does not know how to resolve, which then leads to an epistemic doubt (Candiotto 2015). In this case, we can have the kind of wonder which Plato has called the $\dot{\alpha} \varrho \chi \dot{\eta}$ of philosophy ${ }^{4}$. We can also have softener kinds of wonder which nevertheless trigger the process of inquiry. Consider wonder as "wondering if." Wondering is the beginning of hypothetical thinking which searches a solution to a problem. In this case, the epistemic agent is not facing contradictions; nevertheless, there is something which requires an answer.5 Therefore, the kind of wonder which can be labeled as "epistemic" is an

\footnotetext{
4 "Socrates: My friend, it appears Theodorus' guess about your nature was not far wrong. This wondering of yours is very much the mark of a philosopher-philosophy starts nowhere else but with wondering ( $\mu$ á̀a

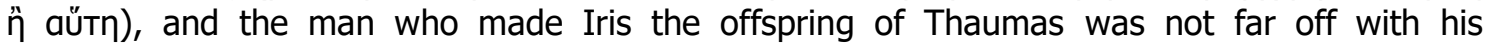
genealogy." (Plat., Theaet. 155d2-d6, tr. Rowe 2015)

${ }^{5}$ This case is closest to Aristotle's conceptualization of wonder: "For it is owing to their wonder

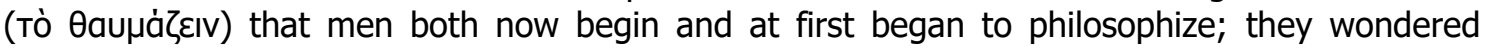
originally at the obvious difficulties, then advanced little by little and stated difficulties about the greater matters, e.g., about the phenomena of the moon and those of the sun and the stars, and about the genesis of the universe. And a man who is puzzled and wonders thinks himself ignorant (whence even the lover of myth is in a sense a lover of wisdom, for myth is composed of wonders); therefore since they philosophized in order to escape from ignorance, evidently they were pursuing science in order to know, and not for any utilitarian end." (Aristotle, Met. A 982b11, tr. Ross in Barnes 1991).
} 
interrogating wonder, that means that its epistemic function is the one of questioning triggered by the recognition of a problem.

I think that it is quite easy to accept that questions, doubts, contradictions are at the beginning of the inquiry. But why should they be experienced in conjunction with an affective state like wonder? Or, discussing this same point from a different perspective: are we sure that this interrogating wonder is still an emotion?

We can reply to this question in different ways. The first is data-based. For example, we can look at the empirical data about the role of wonder in the processes of inquiry and searching if, and under which circumstance, it is significant. The second is analytical and hermeneutical. In this case, we can interpret the phenomenon building some conceptual tools for understanding it. The third is experiential, and it consists of the phenomenology of the very same experience of wonder.

Gallagher et al. (2015) have provided some skillful conceptual tools for understanding the phenomenon. They have suggested to conceptualize as awe the direct and initial experience of amazement and as wonder the reflective experience which leads to open questions (p. 6). What is crucial in this conceptualization is that it puts the affective experience at the beginning, also establishing a nexus with what comes next. However, differentiating awe and wonder implies that yes, there is an affective experience at the beginning, here identified as awe, but what comes next, as a second-order experience, is not affective. In this way, wonder is understood only as questioning, thus losing its emotional dimension. Following this path, wonder would not be an epistemic emotion, but the reflexive process of wondering. So, the emotion, far for being "cognitive" or "intellectual," would only be an immediate and automatic experience of amazement.

The alternative I would like to suggest is the one which finds in the very same experience of wonder both a feeling and a cognitive process. In line with the multi-component view for which emotions are a complex phenomenon made of different components, from physiological reactions to cognitive appraisals, passing through motor expressions, behavioral tendencies, and subjective feelings (Scherer 1984), and with the phenomenological conceptualization of "affective 
intentionality" for which we cannot separate intentionality and phenomenality (Slaby 2008), since bodily feelings are feeling towards (Goldie 2002), I maintain that we cannot relegate emotions to be gut feelings only, neither mental states. In this alternative view I am suggesting, wonder is primarily an experience in which the feeling is not only the one of amazement, but also the feeling of doubt, uneasiness, and the questioning is filled with uncertainty and curiosity. Of course, we can differentiate phases for the sake of clarity, but it is not that first coming awe as an irrational feeling, and then wonder as a more complex cognitive state. On the contrary, we need to conceptualize the experience of wonder in full from the beginning, as an emotional experience which plays an epistemic function.

This is not a matter of terminology but of conceptuality: the point is to take together the feeling and the reflective, what Gallagher et al. (2015) differentiated as awe and wonder. And doing so we can attain what we can legitimately call "epistemic wonder," that I understand as an affective-cum-desiderative state directed at knowing.

It is important to mention that there are plenty of studies on awe as a scientific emotion. Privileging wonder here, I do not want to deny the importance of awe in our life - for example Piff et al. (2015) and Stellar et al. (2017) have clearly explained why awe is vital for going beyond our small self and be open to the other, and how much awe helps in appreciating the everyday beauty. 6 Then, primarily if awe is understood in conjunction with humility, I agree it can play a significant epistemic function (see on this Gottlieb et al. 2018), and many of the results achieved in this field of studies can be very useful for replying positively to my question from a data-based perspective. But the point is that here $\mathrm{I}$ want to theoretically assess why and how wonder can be the beginning of inquiry which, I suggest, should be understood with aporetic states. Awe, on the contrary, can be conceived as a feeling of respect felt in front of the greatness of nature, for example, and in this regard, it is closer to what Kant (2003 [1764]) and then the Romantics have depicted as the feeling of sublime. I thus do think awe is a good candidate for being an epistemic emotion, but it is not the paper's topic. Finally, my rationale in

\footnotetext{
${ }^{6}$ In this regard, there are important studies in the aesthetics of awe and wonder understood as admiration. See Keltner \& Haidt 2003, Fingerhut \& Prinz 2018.
} 
discussing the distinction between awe and wonder suggested by Gallagher et al. (2015) is not to question the different characteristics ascribed to awe and wonder, but to highlight that there is a unitary and complex state which triggers the inquiry, which is affective and cognitive from the beginning. I call this "epistemic wonder" because wonder is the word which in English best describes the unity of the feeling of wonder and wondering, which I find to be crucial at the beginning of the inquiry.

Let us come back to the central thesis of the paper that is the epistimicity of this state. Although the answers to the previous question have, at least in part, already showed that wonder should be taken in account, and have introduced its function, it is still unclear if and why wonder is important for knowing. We can thus reformulate the question in this way: Is wonder essential to undertake a process of inquiry? If not, what is its bonus? ${ }^{7}$

My answer says that, although we can imagine that, under certain circumstances, the processes of inquiring can be undertaken without wonder, wonder provides stronger motivation for knowing. We cannot say that without wonder no inquiry can start, but we can say that with wonder the inquiry assumes more sprint and relevance. Wonder is a booster of knowing. For example, moved by epistemic wonder, the inquirer is triggered to address questions, and she is prone to undertake the laborious process of inquiry for finding some answers. In this case, as I have already introduced, epistemic wonder is aporia-based, and it is thus immediately related to the process of wondering.

There is an obvious objection to this claim: it is entirely possible to facing problems, addressing questions, and being puzzled by aporiai without being moved by it; recognizing an aporia is a purely cognitive act, and it does not require any wonder. The answer here is not only the one which shows that a "pure cognitive state" is fictional since the cognitive and the affective are also always entangled in the real-life processes of knowing, as our best neuroscience has now proved (see on this Colombetti 2014). But it is also the one which points to the existential dimension of wonder-wondering. In fact, the aporia is not a little puzzle, but a

\footnotetext{
7 These questions are related to the more general questions about the role of emotions in knowledge-acquisition, the debate on dispassionate knowledge (Code 1993) and the logic of discovery and scientific inquiry (Jaggar 1989; Kocham 2013).
} 
conflict within a person ${ }^{8}$. As Husserl (1970 [1935]) have noticed - notably discussing the Greek $\theta \alpha u \mu \dot{\alpha} \zeta \varepsilon \iota \nu$ - wonder is embedded in the philosophical life which means that it is part of "the theoretical attitude of philosophical man" depicted as the critical stance of inquiry (p. 286). For Kingwell (2000: 89), Husserl's philosophical wonder invites "not only investigation of the world, but also reflection on the subject who experiences it, and on the experience itself' (Kingwell 2000, p. 89).

The phenomenological analysis binds wonder not only to the experience of the person but also to the philosophical attitude which I have here depicted as aporia-based. This allows us to see that the conflict in place here is not only among beliefs, but it can be depicted as something which impacts the whole style of life of the person. Wonder has been depicted by the Ancient as a $\pi \dot{\alpha} \theta 0 \varsigma$ (Plat., Theaet. 155D2) which is a kind of suffering, at the physical and mental level. It is this conflict which is the aporia-based wonder what can be defined as epistemic, and which the myth has effectively portrayed as the birth-pains of maieutics?

\section{Not only for the pleasure of knowing}

The existential dimension of epistemic wonder highlights that the processes of inquiry are not only motivated by the pleasure of knowing, but also by the desire of overcoming the distress provoked by the unknown, and specifically to the aporetic states, by recognizing contradictions and ignoring how to escape from them. In this section, I want to elucidate the hedonic valence of epistemic wonder since it is crucial for analyzing its epistemic value from a phenomenological perspective.

\footnotetext{
${ }^{8}$ As when Socrates said that propositions are "battling with themselves in our souls" Theaet. 155b5. See Politis 2015.

9 "Those who get together with me have something else in common with women in childbirth: they suffer birth-pains, and a sense of helplessness (ánopia) fills them, night and day-much more, indeed, than a woman, and my expertise is able both to awaken and put a stop to the pain" (Theaet. 151a5-b2).
} 
Let us come back to my experience. My wondering has been triggered not only by the proposition "Everything is full of wonder," but also by the picture of a dead leaf. How can a dead leaf be full of wonder?

Wonder is not just the marvelous which can be experienced in admiring the blossoming of a cherry tree in the spring. But, as Heidegger (1991) has highlighted, wonder comes from the wondrous, the unexpected, which produces angst, anxiety, and anguish. These feelings are embedded in our human existence as finite beings towards death. If we follow this conceptualization, the questioning is triggered by the anxiety of the unknown, and by the supreme object of terror, which is death. That is why a dead leaf can be full of wonder: it makes us think about our finitude and prompt us to address questions about the nature of life and death.

I cannot argue for the validity of this conceptualization here, but I am mentioning it because it has the value of exposing the existential dimension embedded in the process of inquiry. Understanding inquiry from this perspective allows us to understand that it is not only out of a pleasurable curiosity that we ask questions. Moreover, the pleasure embedded in the process is very often the release from suffering, that is getting an answer beyond the aporetic state. The aporetic state is not pleasurable in itself, but it is quite painful indeed; his positive value is provided by its epistemic function which prospects the resolution of the suffering if a process of inquiry is undertaken. Empirical studies have shown how much pain is a motivational force, able to focus the attention on resolving the problem that creates it. In our case, the pain related to the aporetic state enhances the motivation for going beyond them and, finally, generating knowledge (Brady 2009, 2018b). This means that wonder as epistemic emotion is a booster of knowing not only because it triggers the pleasurable curiosity of knowing more about a thing, but also, and more significantly, because it motivates the inquirer of going beyond the uneasiness of not-knowing.

Epistemic wonder can thus be defined as an ambivalent emotion - both pleasurable and painful, under different respects - since the questioning brings together the enthusiastic merveille which asks the why of everything, and the perplexity which questions the limits of knowledge and life. Not only, but epistemic 
wonder also brings the desire of overcoming the suffering of ignorance for the pleasure of getting answers. This complex and multifaceted hedonic level is functional to the positive epistemic role of triggering a process of inquiry since it contributes to the need of "wondering." No wondering if everything is precise and clear, but much more wondering if a problem creates a conflict within ourselves.

Cognitive science is now proving that our brains try to overcome uncertainty building patterns of predictability (Clark 2016). What is relevant for my argument is that emotions seem to be built from predictions (Wilkinson et al. 2019) and that it is the surprise brought by the unexpected what obliges the brain to continuously remake the patterns for replying to the prediction-errors. The unexpected leads to prediction errors and these errors are what first provoke the predictions revision and, finally, to improve future performance. Understanding the interrogating wonder from this perspective, in its entanglement with surprise and the need for certainty, is another way of recognizing its epistemic value.

\section{Wondering until the end?}

The teleology which links inquiry and epistemic success seems to force wonder to be overcome by the achievement of the answer. The final question I want to address in this paper is thus the one which asks if epistemic wonder can be definitely overcome through the acquisition of knowledge.

It is undeniable that the epistemic function I argued for wonder in this paper, which is motivation to knowing in the broad sense, and aporiai solving specifically, is a function which is performed at the beginning of the inquiry. However, this does not mean that this function comes only once. As I think we can easily acknowledge scrutinizing our experience of inquiry, new aporiai arises after having solved the previous ones. Not only, after some time we may need to come back to the presumably solved aporia for revising it - and many times it is a good practice to revise our answer for being sure of not having accepted them acritically. This means that the process of inquiry is continuous and recurrent, it cannot be understood as a mere line which blindly proceeds until the end, understood as the knowledgeacquisition. On the contrary, the process of inquiry is made of dead ends, returns, 
and local pieces of knowledge. The pragmatist tradition has excellently highlighted the never-ending process of inquiry, but also its discontinuous character (see on this English 2013). The aporiai, as interruptions of thinking, can be seen in this regard as new beginnings of inquiry as a learning process. So, this also means that the process of inquiry always generates new questions, new wonders-wondering.

Then, we should admit that the unexpected is always ready to knock on our door, although we want to escape from it. However, this fundamental uncertainty which pervades our existence is what prompts scientific inquiry and thus what allows us to make the most significant discoveries. The best scientists, which are the experts of inquiry, know it very well. That is why they strenuously continue to address new questions, after thousands of answers. As Albert Einstein (1935) majestically said, scientists should be full of wonder since "to whom the emotion is a stranger, who can no longer pause to wonder and stand wrapped in awe, is as good as dead - his eyes are closed" (Einstein 1935 in White Patrick \& Miller Chapman 1935: 44). The interrogating wonder that is epistemic is thus not only the mark of the philosopher, as Plato said (Theaet. 155d2-d6), but of everyone who makes aporiai the beginning of the inquiry, from the ordinary woman who by chance is struck by seeing a dead leaf falling from the tree to the expert knower who has made of wonder one of the motivations of her expertise. This means that we have another reason for denying that wonder is only at the beginning of the inquiry. In fact, it is not only the feeling of who is at the first steps of a process of inquiry, namely the "beginner." But it should be experienced throughout the process of inquiry by the expert knower too, as a motivation to questioning. In this sense, epistemic wonder is a crucial component of the virtuous epistemic character of the critical knower ${ }^{10}$.

\footnotetext{
${ }^{10}$ I cannot develop further this point here because it would require a full argument by its own, but it points to the conceptualization of epistemic emotions as parts of the intellectual virtues of the virtuous knower. See on this Candiotto 2017a, 2017b.
} 


\section{Conclusion}

In this paper, I argued that wonder is epistemic, in the strong sense of an experience directed at knowing, iff it is aporia-based. I depicted epistemic wonder as an affective-cum-desiderative experience which is cognitive from the beginning in the sense of knowledge-directed. The epistemic function of wonder is, therefore, the one of motivation for questioning. I also conceptualized its hedonic valence as ambivalent, showing why this allows wonder of being a booster of knowing. Highlighting the epistemic value of wonder, my analysis has thus confirmed the famous motto for which wonder is the beginning of the inquiry, but it has also specified what we need to mean for the beginning of the inquiry. The beginning of inquiry is not only the first step of a linear process which does not need it any more after the start, but it comes back every time new questions arise, and new answers should be revised. I concluded saying that this also means that epistemic wonder as motivation to questioning should be conceived as an important component of the character traits of the virtuous knower.

\section{Acknowledgment}

I am wondering about wonder for many years, and I discussed my ideas with many colleagues and friends I cannot thank here. But at least Vasilis Politis should be mentioned, with whom I wrote a paper on the notion of wonder in Plato: the historical analysis of the concept I made with him is at the ground of this paper and has stimulated my theoretical investigation. I am grateful to Jan Slaby and the participants to the Emotion Colloquium at FU Berlin for the great questions and insightful comments addressed to a preliminary version of the argument I presented here. This paper arises from the project "Bond. Positive emotions in group cognition" funded by the Alexander von Humboldt Foundation at FU Berlin. 


\section{References}

Aristotle. 1991. The Complete Works of Aristotle: The Revised Oxford Translation. Ed. J. Barnes. Princeton: Princeton University Press.

Brady, M. S. 2018a. Emotion: The basics. Abingdon: Routledge.

Brady, M. S. 2018b. Suffering and Virtue. Oxford: Oxford University Press.

Brady, M. S. 2013. Emotional Insight. The Epistemic Role of Emotional Experience. Oxford: Oxford University Press.

Brady, M. S. 2009. "Curiosity and the Value of Truth." In A. Haddock, A. Millar, D. Pritchard (Eds.), Epistemic V alue, pp. 265-283. Oxford: Oxford University Press.

Brun, G., U. Doğuoğlu, and D. Kuenzle (eds.). 2008. Epistemology and Emotions. Aldershot: Ashgate.

Candiotto, L. 2019a. "Epistemic Emotions and the Value of Truth.". Acta Analytica, https://doi.org/10.1007/s12136-019-00416-x

Candiotto, L. 2019b. Ed. The V alue of Emotions for Knowledge. London: Palgrave Macmillan.

Candiotto, L. 2019c. "The Virtues of Epistemic Shame in Critical Dialogue." in Interdisciplinary Perspectives on Shame: Theory, Method, Norms, Cultures, and Politics, ed. C. Mun, pp. 75-94. Lexington Books/Rowman \& Littlefield.

Candiotto, L. 2017a. "Epistemic emotions: the building blocks of intellectual virtues." Studi di estetica, XLV, IV SERIE, N. 7, pp. 7-25.

Candiotto, L. 2017b. "The route of goodness. Epistemic emotions, self-realization, and perfection". Thaumàzein 4: 243-258, special issue "Philosophy of Birth: Emotions and the Formation of Person," ed. G. Cusinato.

Candiotto, L. 2015. "Aporetic State and Extended Emotions: the Shameful Recognition of Contradictions in the Socratic Elenchus." Etica e Politica/Etbics \& Politics, XVII, 2015(2): 233-248, special issue "The Legacy of Bernard Williams's Shame and Necessity," ed. A. Fussi.

Candiotto, L., Politis, V. (forthcoming). "Epistemic wonder and the beginning of the enquiry: Plato's Theaetetus $155 \mathrm{~d} 2-4$ and its wider significance". In L. Candiotto, O. Renaut (Eds.), Emotions in Plato. Leiden: Brill.

Clark, A. 2016. Surfing Uncertainty: Prediction, Action, and the Embodied Mind. Oxford: Oxford University Press.

Code, L. 1993. "Taking Subjectivity into Account." In L. Alcoff, E. Potter (Eds.), Feminist Epistemologies, pp. 15-48. New York and London: Routledge.

Colombetti, G. 2014. The Feeling Body: Affective Science Meets the Enactive Mind. Cambridge, MA: MIT Press. 
Deonna, J. 2006, "Emotion, Perception and Perspective". Dialectica 60: 29-46.

De Sousa, R. 2008. "Epistemic Feelings." In G. Brun, U. Doğuoğlu, and D. Kuenzle (Eds.), Epistemology and Emotions, pp. 185-204. Aldershot: Ashgate.

Döring, S. 2007. "Seeing What to Do: Affective Perception and Rational Motivation." Dialectica 61: 363-394.

Einstein, A. 1935. The World as I See It, tr. A. Harris. London: John Lane The Bodley Head.

English, A. 2013. Discontinuity in Learning. Dewey, Herbart and Education as Transformation. Cambridge: Cambridge University Press.

Fingerhut, J., Prinz, J. J. 2018. "Wonder, Appreciation, and the Value of Art." Progress in Brain Research 237: 107-128.

Gallagher, S., Reinerman-Jones, L., Janz, B., Bockelman, P., Trempler, J., 2015. A Neurophenomenology of Awe and Wonder. Basingstoke: Palgrave Macmillan.

Goldie, P. 2002. "Emotions, feelings and intentionality." Phenomenology and the Cognitive Sciences, 1, 235-254.

Gottlieb, S., Keltner, D., Lombrozo, T. 2018. "Awe as a Scientific Emotion." Cognitive Science 42: 2081-2094.

Hookway, C. 2008. "Epistemic Immediacy, Doubt and Anxiety: on a Role for Affective States in Epistemic Evaluation," pp. 51-65. In G. Brun, U. Doğuoğlu, and D. Kuenzle (Eds.), Epistemology and Emotions. Aldershot: Ashgate.

Hookway, C. 2003. "Affective States and Epistemic Immediacy," Metaphilosophy, 34:1/2, pp. 78-96.

Heidegger, M. 1991 [1955]. What is that_Philosophy? Tr. E.T.H. Brann. Annapolis: St. Johns College.

Husserl, E. 1970 [1935]. "The Vienna Lecture." In The Crisis of European Sciences and Transcendental Phenomenology, tr. D. Carr, pp. 269-400. Evanston: Northwestern University Press.

Jaggar, A. 1989. "Love and Knowledge: Emotion in Feminist Epistemology." Inquiry 32(2): 151-176.

Johnston, M. 2001. "The Authority of Affect". Philosophy and Phenomenological Research, 63: 181-214.

Kant, I. 2003 [1764]. Observations on the Feeling of the Beautiful and Sublime, tr. J. T. Goldthwait. University of California Press.

Keltner, D., Haidt, J., 2003. "Approaching awe, a moral, spiritual, and aesthetic emotion". Cognition and Emotion 17(2): 297-314.

Kingwell, M. 2000. "Husserl's sense of wonder." The Philosophical Forum 31(1): 85-107. 
Kochan, J. 2013. "Subjectivity and emotion in scientific research." Studies in History and Philosophy of Science Part A 44(3): 354-362.

Livet, P. 2016. "Emotions, Beliefs, and Revisions." Emotion Review 8 (3): 240-249.

Mitchell, J. 2017. "The Epistemology of Emotional Experience." Dialectica 71(1): 57-84.

Morton, A., 2010. "Epistemic emotions." In P. Goldie (Ed.), The Oxford handbook of philosophy of emotion, pp. 385-99. Oxford: Oxford University Press.

Piff, P. K., Dietze, P., Feinberg, M., Stancato, D. M., Keltner, D., 2015. "Awe, the Small Self, and Prosocial Behaviour." Journal of Personality and Social Psychology, 108 (6): 883-889.

Plato. 2015. Theaetetus and Sophist, tr. C. J. Rowe. Cambridge: Cambridge University Press.

Politis, V. 2015. The Structure of Enquiry in Plato's Early Dialogues. Cambridge: Cambridge University Press.

Scheffler, I., "In praise of the cognitive emotions" and other essays in the philosophy of education, New York-London, Routledge, 1991.

Scherer, K. R. 1984. "On the Nature and Function of Emotion: A Component Process Approach." In K. R. Scherer, P. Ekman (Eds.), Approaches to Emotion, pp. 293-317. Hillsdale: Erlbaum.

Slaby, J. 2008. "Affective Intentionality and the feeling body", Phenomenology and Cognitive Science, 7: 429-444.

Stellar, J. E., Gordon, A. M., Piff, P. K., Cordaro, D., Anderson, C. L., Bai, Y., Maruskin, L. A., Keltner, D. 2017. "Self Transcendent Emotions and Their Social Functions: Compassion, Gratitude, and Awe Binds Us to Others Throught Prosociality." Emotion Review, 9 (3): 200-207.

Stocker, M., 2004. "Some considerations about intellectual desire and emotions." In R. C. Solomon (Ed.), Thinking about feeling, pp. 135-48, New York, Oxford University Press, 2004.

Tappolet, C. 2000. Émotions et V aleurs. Paris: Presses Universitaires de France.

White Patrick, G. T., Miller Chapman, F. 1935. Introduction to Philosophy. London: George Allen \& Unwin.

Wilkinson, S., Deane, G., Nave, K., Clark, A. 2019. "Predictive Processing and the Nature of Emotion." In L. Candiotto (Ed.), The Value of Emotions for Knowledge, pp. 101-119. London: Palgrave Macmillan. 